Review began 01/11/2022 Review ended 01/17/2022 Published 01/19/2022

๑) Copyright 2022

Behera et al. This is an open access article distributed under the terms of the Creative Commons Attribution License CC-BY 4.0., which permits unrestricted use, distribution, and reproduction in any medium, provided the original author and source are credited.

\section{Replaced Right Hepatic Artery Arising From the Celiac Trunk: A Rare and Challenging Anatomical Variant of the Pancreaticoduodenectomy Procedure}

\author{
Arunanshu Behera ${ }^{1}$, Cherring Tandup ${ }^{1}$, Uttam K. Thakur ${ }^{1}$, Swapnesh Sahu ${ }^{2}$, Deepak Sutrave ${ }^{3}$ \\ 1. General Surgery, Postgraduate Institute of Medical Education and Research, Chandigarh, IND 2. General and \\ Colorectal Surgery, Postgraduate Institute of Medical Education and Research, Chandigarh, IND 3. General Surgery, \\ Post Graduate Institute of Medical Education and Research, Chandigarh, IND
}

Corresponding author: Cherring Tandup, ctandup@gmail.com

\begin{abstract}
Anatomic variation of the hepatic artery is common and often seen in patients with periampullary carcinoma undergoing a pancreatic duodenectomy. Replaced right hepatic artery from the superior mesenteric artery is the most common variant encountered. Here we present a rare case of an unclassified pattern of the variant anatomy of replaced right hepatic artery originating from the celiac trunk along with an accessory left hepatic artery arising from the left gastric artery in a patient with periampullary carcinoma undergoing pancreaticoduodenectomy.
\end{abstract}

Categories: Radiology, Gastroenterology, General Surgery

Keywords: periampullary carcinoma, anatomic variation, pancreaticoduodenectomy, celiac trunk, hepatic artery

\section{Introduction}

Hepatic arterial anatomical variation is often encountered in patients with pancreatic cancer undergoing pancreaticoduodenectomy (PD). Hepatic arterial anatomical variation is seen in up to $17 \%$ of preoperative visceral angiograms [1]. Many classification systems have been described in the literature to categorize the variations [1]. It is important to be aware of variant hepatic arterial anatomy to avoid inadvertent injury or ligation leading to poor outcome, morbidity, and mortality. Here we present a rare case report of an unclassified pattern of arterial anomaly encountered in a patient with periampullary carcinoma undergoing PD.

\section{Case Presentation}

A 59-year-old male presented to the surgery clinic with pain in the epigastric region for eight months. He also gave a history of obstructive jaundice for one month, which was gradually progressive. There was an unintentional weight loss of $6 \mathrm{kgs}$ over the past six months and was associated with anorexia. On physical examination, his performance status was found good, Icterus was present. Per abdominal examination was within normal limits. His total bilirubin was $8 \mathrm{mg} / \mathrm{dL}$, with raised alkaline phosphatase $350 \mathrm{U} / \mathrm{L}$ (reference range: 40-128 U/L). Cancer antigen (CA) 19.9 was raised to $423 \mathrm{IU} / \mathrm{L}$.

Ultrasound abdomen showed dilated intrahepatic biliary radicals and common bile duct. Contrast tomography with colored three-dimensional angiography scan showed a $3.4 \mathrm{~cm} \mathrm{x} 2.6 \mathrm{~cm}$ hypoenhancing mass in the pancreatic head abutting the right hepatic artery (RHA) for a length of $2.2 \mathrm{~cm}$ distal to its origin from the celiac artery. The accessory left hepatic artery (supplying to segments $4 \mathrm{a}$ and $4 \mathrm{~b}$ ), was arising from the left gastric artery (Figure 1). 


\section{Cureus}

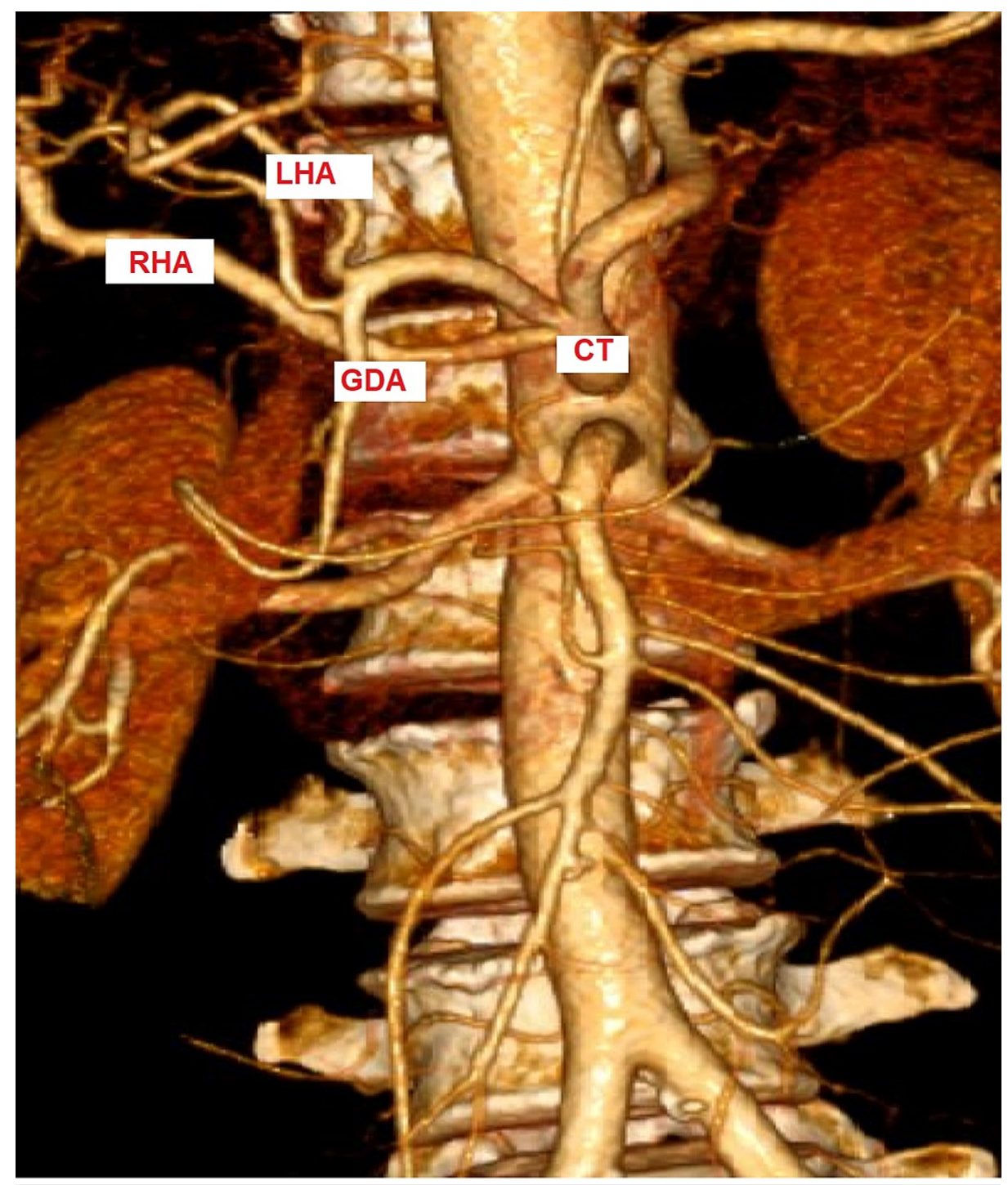

FIGURE 1: Three-dimensional colored computed tomography showing replaced right hepatic artery arising from the celiac trunk.

CT- Celiac Trunk, GDA- Gastro-Duodenal Artery, LHA- Left Hepatic Artery, RHA- Right Hepatic Artery

During PD, the intra-operative right hepatic artery variant (Figure 2) was identified, arising directly from the celiac trunk, coursing posterior to the portal vein, and adhering to retro-pancreatic lymph node which was dissected. Accessory left hepatic artery (LHA) was arising from the left gastric artery (LGA). Superior mesenteric artery and vein were normal. Histopathology report showed moderately differentiated adenocarcinoma of the periampullary region with pathological staging pT3pN2pM0. The postoperative course was uneventful and the patient was discharged in a satisfactory condition. 


\section{Cureus}

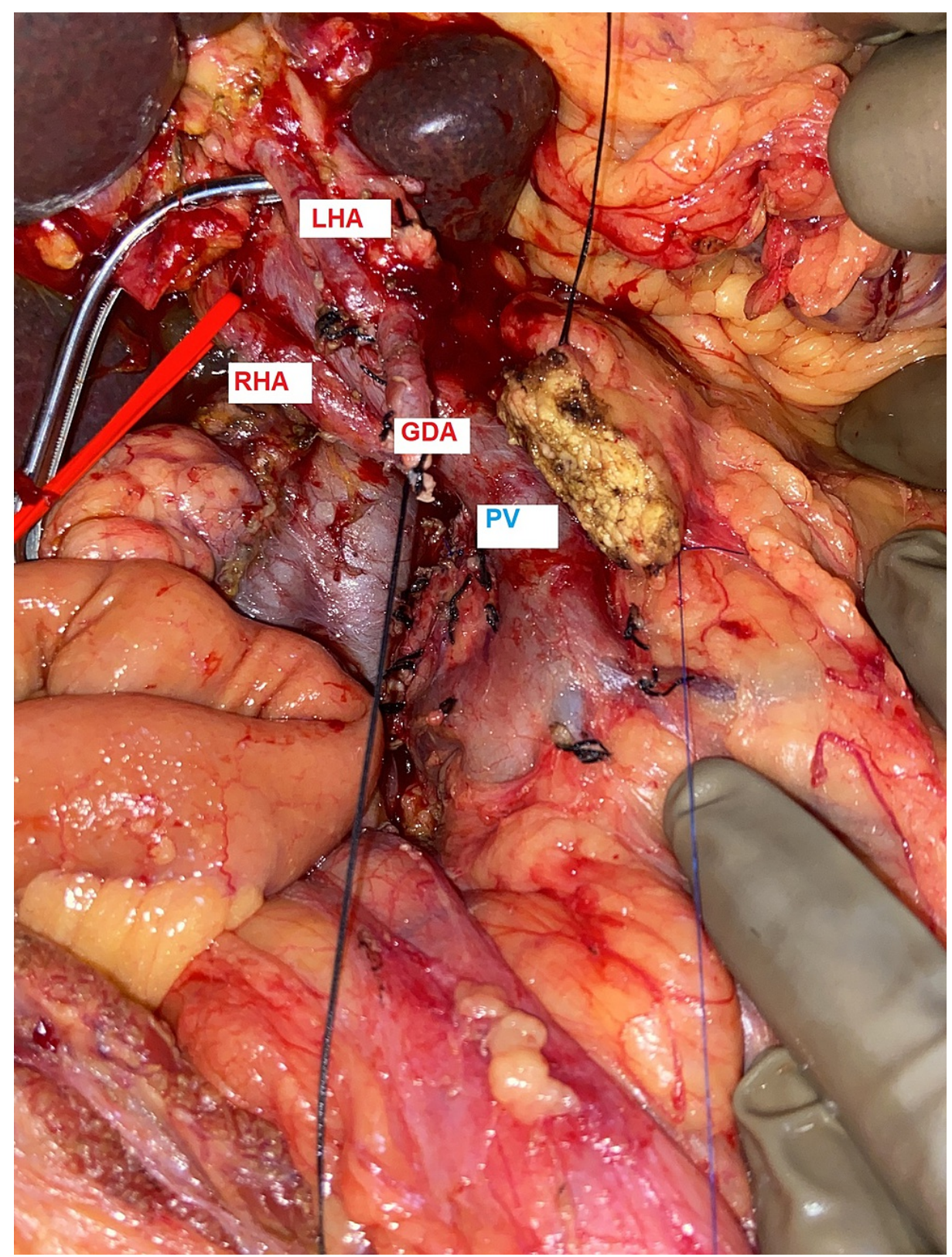

FIGURE 2: Intraoperative image showing right hepatic artery looped in a red sling, coursing posterior and lateral to the portal vein, along with long gastroduodenal artery stump.

GDA- Gastro-Duodenal Artery, LHA- Left Hepatic Artery, RHA- Right Hepatic Artery, PV- Portal Vein

\section{Discussion}

Pancreaticoduodenectomy is the only potentially curative treatment option for periampullary carcinoma. The procedure itself is complicated, arterial anatomical variation makes it further complex and there is a possible risk of inadvertent vascular injury or ligation, which may result in increased blood loss and prolonged operation time. Recognition and management of aberrant RHA are of paramount importance during PD. In 1955, Michels categorized and published hepatic arterial anatomical variations after investigating 200 cadavers and also highlighted the differences between aberrant and accessory hepatic arteries and their importance [2]. The term replaced hepatic artery refers to one having an aberrant or anomalous origin, whereas the accessory artery has an abnormal origin and supplies a section of the liver along with another artery. The index case is an unclassified pattern of variation in which replaced RHA is originating from the celiac trunk and an accessory LHA is seen arising from LGA.

Iatrogenic cessation of arterial flow to the liver during pancreaticoduodenectomy often leads to short and long-term impacts on the outcome of the procedure. Rapid restoration of arterial flow is indicated whenever 
it is technically possible and can prevent early fatal complications and late biliary stenosis [3]. A review of literature by Shukla et al. analyzed reports between 1960 to 2008, concerning the influence of hepatic arterial anatomical variation on pancreaticoduodenectomy outcomes [4]. They concluded that awareness of preoperative hepatic arterial anatomical variation would decrease intraoperative vascular injury and thereby associate complications like postoperative hemorrhage and bilioenteric anastomotic leaks. When unexpected hepatic arterial variants are encountered intraoperatively, there is a high chance of vessel injury resulting in hemorrhage, hepatic ischemia, abscess, liver enzyme elevation, and anastomotic biliary leaks. In cases that require aberrant hepatic artery resection during PD due to tumor conditions, surgeons should carefully monitor the postoperative course, while keeping in mind the possible necessity of urgent hepatectomy due to liver necrosis, usually in cases having replaced left hepatic artery [5]. Surgical and oncological outcomes of pancreaticoduodenectomy remain unaffected by the presence of ARHA provided that the anatomy is delineated and appropriately managed [6-8]. It is of the utmost importance to have a preoperative knowledge of variations of arterial anatomy for safe performance of hepatopancreatic-biliary surgery and obtain an optimal result.

\section{Conclusions}

Pancreaticoduodenectomy is a complex and technically demanding procedure and is still associated with high morbidity and mortality rates. The presence of a variation in hepatic arterial anatomy may increase the risk of intraoperative vascular damage. However, they are not considered a contraindication and with good surgical experience, the procedure may be done. Consequently, preoperative identification and interpretive anticipation are necessary to prevent complications.

\section{Additional Information \\ Disclosures}

Human subjects: Consent was obtained or waived by all participants in this study. Conflicts of interest: In compliance with the ICMJE uniform disclosure form, all authors declare the following: Payment/services info: All authors have declared that no financial support was received from any organization for the submitted work. Financial relationships: All authors have declared that they have no financial relationships at present or within the previous three years with any organizations that might have an interest in the submitted work. Other relationships: All authors have declared that there are no other relationships or activities that could appear to have influenced the submitted work.

\section{References}

1. Gkaragkounis A, Fanariotis M, Tepetes K, Fezoulidis I, Vassiou K: Celiac trunk and hepatic arteries: anatomical variations of liver arterial supply as detected with multidetector computed tomography in 1,520 patients and its clinical importance. Clin Anat. 2020, 33:1091-101. 10.1002/ca.23511

2. Michels NA: Newer anatomy of the liver and its variant blood supply and collateral circulation . Am J Surg. 1966, 112:337-47. 10.1016/0002-9610(66)90201-7

3. Landen S, Ursaru D, Delugeau V, Landen C: How to deal with hepatic artery injury during pancreaticoduodenectomy. A systematic review. J Visc Surg. 2017, 154:261-8. 10.1016/j.jviscsurg.2017.05.013

4. Shukla PJ, Barreto SG, Kulkarni A, Nagarajan G, Fingerhut A: Vascular anomalies encountered during pancreatoduodenectomy: do they influence outcomes?. Ann Surg Oncol. 2010, 17:186-93. 10.1245/s10434009-0757-1

5. Yamamoto M, Zaima M, Yamamoto H, et al.: Liver necrosis shortly after pancreaticoduodenectomy with resection of the replaced left hepatic artery. World J Surg Oncol. 2017, 15:77. 10.1186/s12957-017-1151-2

6. Jah A, Jamieson N, Huguet E, Praseedom R: The implications of the presence of an aberrant right hepatic artery in patients undergoing a pancreaticoduodenectomy. Surg Today. 2009, 39:669-74. 10.1007/s00595009-3947-3

7. Eshuis WJ, Olde Loohuis KM, Busch OR, van Gulik TM, Gouma DJ: Influence of aberrant right hepatic artery on perioperative course and longterm survival after pancreatoduodenectomy. HPB (Oxford). 2011, 13:161-7. 10.1111/j.1477-2574.2010.00258.x

8. Rammohan A, Palaniappan R, Pitchaimuthu A, et al.: Implications of the presence of an aberrant right hepatic artery in patients undergoing pancreaticoduodenectomy. World J Gastrointest Surg. 2014, 6:9-13. 10.4240/wjgs.v6.i1.9 